\title{
Busbar current transducer with suppression of external fields and gradients
}

\author{
Pavel Ripka, Andrey Chirtsov
}

Czech Technical University, Faculty of Electrical Engineering, Prague, 16627, Czech Republic

\begin{abstract}
Yokeless busbar current transducers with circular sensor array achieve high precision when replacing Hall sensors by microfluxgate. Limited field range of fluxgate can be compensated by inverse design with sensorsinside the busbar. In this paper we present novel scheme how to improve immunity of such sensor against external field and field gradient. We also examine crosstalk error for external currents close to the transducer. Using five microfluxgate sensors we designed 400 A current transducer which has suppression of 93000 for currents in $40 \mathrm{~cm}$ vicinity.
\end{abstract}

Index Terms-Current transducer, fluxgate

\section{INTRODUCTION}

Y OKELESS BUSBAR current sensors are cheap and compact, but they are sensitive to external magnetic fields and field gradients [1,2]. We have described current transducer based on a couple of microfluxgate sensors [3] inside the cylindrical hole in the busbar [4,5]. The advantage of this transducer is high range and small size compared to similar transducer based on circular sensor array around the conductor [6]. Compared to Hall current sensors $[7,8]$, fluxgate current sensor has 10 -times better stability. Solution based on AMR has 10-times lower range due to the small saturation field of AMR sens ors [9].

Using only 2 sensors in differential mode gives only s mall immunity agains crosstalk: in [2] we have shown that lateral current in $15 \mathrm{~cm}$ vicitity is suppressed only by the factor of 66. In [10] we have suggested that better suppression of the magnetic fields generated by external currents can be achieved by using four microfluxgate sensors: two of them are active and they measure $\mathrm{y}$-component of the field at points $A$ and $C\left(B_{A y}\right.$ and $\left.B_{C y}\right)$ the other two measure both field components at point $\mathrm{B}\left(\mathrm{B}_{\mathrm{Bx}}\right.$ and $\left.\mathrm{B}_{\mathrm{By}}\right)$. Unfortunatelly this approach can be effective only for the case of known geometry of the external currents or when the external currents are also measured.

However, in general case the position and size of the external current is not always known and the interference field can be generated by several currents simultaneously. Significant magnetic fields can also by generated by coils and by magnetic materials (both hard and soft in external field) in the vicinity of the transducer.

In this paper we therefore suggest more general approach and we show the design of current transducer which is immune to external homogeneous fields and first order field gradients. This means that our new solution does not

Manuscript received April 1, 2015; revised May 15, 2015 and June 1, 2015; accepted July 1, 2015. Date of publication July 10, 2015; date of current version July 31, 2015. Corresponding author: P. Ripka (e-mail: ripka@fel.cvut.cz).

Color versions of one or more of the figures in this paper are available online at http://ieexplore.ieee.org.

Digital Object Identifier (inserted by IEEE). perfectly compensate the field from external conductors, but effectively suppresses their influence, as higher order gradients from distant currents are small.

We start from 2-D FEM simulation and find points, which can be used to compensate the influence of the external fields and field gradients. Using the field values at this points we derive the formula for the measured current. Finally we verify the design by measurement.

\section{TransDucer Design}

Fig. 1 shows the current busbar with fluxgate scanning sensor array inserted into the hole and Fig. 2 shows field dis tribution on a busbar cross section. The size of the copper busbar is $6 \times 1 \mathrm{~cm}$ and the hole diameter is $19 \mathrm{~mm}$. The DC current value for this simulation was $1000 \mathrm{~A}$. The sensor array shown on the photograph in Fig. 1 consists of six sens ors - three of themare visible as a row with $6 \mathrm{~mm}$ pitch, which measures $\mathrm{B}_{\mathrm{y}}$ in positions $\mathrm{A}, \mathrm{B}$ and $\mathrm{C}$. The other 3 sensors are on the opposite side of the PCB and they measure $B_{x}$ at the same points. By moving th is sensor array in y direction we can scan the field values at otherpositions above the central plane and verify the simulations. In general the fit between our measurements and FEM simulations is within $5 \%$. After performing the simulation and measurement exercise we fixed the sensor optimum position for the final transducer design, which is shown in Figs. 6 and 7.

All previously published current transducers of this type such as [3] and [7] used sensors in the central line (positions $\mathrm{A}$ and $\mathrm{C}$ ) measuring $\mathrm{B}_{\mathrm{y}}$. The fact that $\mathrm{B}_{\mathrm{Ay}}$ and $\mathrm{B}_{\mathrm{Cy}}$ have oppositesign was used to suppress homogeneous external field $\mathrm{B}_{0}$. However, calculated field distribution of $\mathrm{B}_{\mathrm{y}}$ along the A-C line is linear (Fig. 3) and this means that external $\mathrm{dB}_{\mathrm{y}} / \mathrm{dx}$ field gradient cannot be suppressed. Possible solution of this problem would be to change the busbar geometry in order to achieve significantly non-linear field profile and evaluate second-order gradient from the measured current. We have made extensive simulations with various geometries but we never achieved significant non-linearity. Instead of that we decided to find alternative sens or positions outside the central A - C line. Fig. 4 which shows $\mathrm{B}_{\mathrm{y}}$ field calculated along the D-E line. The field profile in the vicinity of central point $\mathrm{A}$ is flat which 
indicates good sensor stability against small sensor displacement caused by manufacturing tolerances and temperature dilatations. On the profile we can also find positions where the field from the busbar current is zero. These points could be theoretically used to locate compensation sensors to suppress field gradients. However, the sensitivity in these points is steeply changing which makes them susceptible to the mentioned displacements.

\section{FIG. 1 HERE}

\section{FIG. 2 HERE}

FIG. 3 HERE

FIG. 4 HERE

The novelty of our approach is that we use $B_{x}$ instead of $B_{y}$. $B_{x}$ response to the measured current does not change sign when mirroring around the $\mathrm{y}$ axis. At $\mathrm{H}$ and I points the calculated sensitivity is the same, $5 \mathrm{mT} / 1000 \mathrm{~A}$ as shown in Fig. 5. Due to the $2 \mathrm{mT}$ maximum range of the DRV425 sens or the actual current range will be only $400 \mathrm{~A}$. Summing $\mathrm{B}_{\mathrm{Hx}}+\mathrm{B}_{\mathrm{Ix}}$ therefore does not suppress homogeneous external field $B_{0 x}$, but instead of that it suppresses $d_{B} / d x$ field gradient. This type of gradient is not typical for long conductors, but for dipolar sources such as coils and permanent magnets. This setup is also completely ins ensitive to external currents in y (superior) direction. The dependence on $\mathrm{B}_{0 \mathrm{x}}$ can be suppressed by using the third $\mathrm{x}$ sens or at the central point A. Remaining is the dependence on $\mathrm{dB}_{\mathrm{x}} / \mathrm{dy}$ field gradient. Here we face the similar problem as before, because $B_{x}$ response to the measured current change sign when mirroring around the $\mathrm{x}$ axis. Fortunately, the calculated field dis tribution along the DEline is strongly non-linear and thus the external $\mathrm{dB}_{\mathrm{x}} /$ dy field gradient can be suppressed. This is documented by the $\mathrm{B}_{\mathrm{x}}$ profile calculated along the DE line (Fig. 5). We achieve the required compensation by using additional sensor located at $\mathrm{J}$ and eventually also K point. While $\mathrm{B}_{\mathrm{Jy}}-\mathrm{B}_{\mathrm{hy}}$ is insensitive to the measured current, this value depends only on $\mathrm{dB}_{\mathrm{y}} / \mathrm{dx}$ field gradient.

The schematics of our novel transducer design is shown in Fig. 6: it consists of five sensors B, H, I, J and K. The sensor position corresponds to stars in previous figures. Figure 7 shows the final sensor board inserted into the busbar.

\section{FIG. 5 HERE}

\section{FIG. 6 HERE}

\section{FIG. 7 HERE}

\section{A. Finding the compensation formula}

Let us as sume that theexternal field at point $B$ equals to $B_{0}$ and the external field gradient $\mathrm{dB} / \mathrm{dx}=\mathrm{B}_{1} / 6 \mathrm{~mm}, \mathrm{~dB} / \mathrm{dy}=$ $\mathrm{B}_{2} / 10 \mathrm{~mm}$.

and let us denote $B_{m}$ as the field from the measured current.

Then we can write

$$
\begin{aligned}
& \mathrm{B}_{\mathrm{B}}=\mathrm{B}_{0} \\
& \mathrm{~B}_{\mathrm{H}}=\mathrm{B}_{0}-\mathrm{B}_{1}+\mathrm{B}_{2}+\mathrm{B}_{\mathrm{m}} \\
& \mathrm{B}_{1}=\mathrm{B}_{0}+\mathrm{B}_{1}+\mathrm{B}_{2}+\mathrm{B}_{\mathrm{m}} \\
& \mathrm{B}_{\mathrm{J}}=\mathrm{B}_{0}-\mathrm{B}_{1}+2 \mathrm{~B}_{2}+\mathrm{B}_{\mathrm{m}} \\
& \mathrm{B}_{\mathrm{K}}=\mathrm{B}_{0}+\mathrm{B}_{1}+2 \mathrm{~B}_{2}+\mathrm{B}_{\mathrm{m}} \\
& \mathrm{B}_{\mathrm{H}}+\mathrm{B}_{1}-2 \mathrm{~B}_{\mathrm{B}}=2 \mathrm{~B}_{2}+2 \mathrm{~B}_{\mathrm{m}} \\
& \mathrm{B}_{\mathrm{J}}+\mathrm{B}_{\mathrm{K}}-2 \mathrm{~B}_{\mathrm{B}}=4 \mathrm{~B}_{2}+2 \mathrm{~B}_{\mathrm{m}}
\end{aligned}
$$

Finaly the formula for the measured field $\mathrm{B}_{\mathrm{m}}$ is

$$
B_{m}=B_{H}+B_{l}-\left(B_{J}+B_{K}\right) / 2-B_{B}
$$

From this formula the resulting sensitivity for $B_{m}$ is still 5 $\mu \mathrm{T} / \mathrm{A}$. As the noise of individual sensors is not correlated, the fluxgate sensor noise is suppressed by $\sqrt{ } 4$.

\section{VERIFICATION}

Fig. 8 shows field caused by external current in the location of all sensors. The field is calculated by two methods: analytically, supposing that the external current flows through the idealized single line conductor, and by FEM taking into the account the real size of the $60 \mathrm{~mm} \times 10$ $\mathrm{mm}$ current bar. It is clear that for distances larger than 20 $\mathrm{mm}$ the size of the externalconductor does not influence the results.

\section{FIG. 8 HERE}

Fig 9 shows the same values measured by uncalibrated sensors. The difference from ideal results shown in Fig 6 were analyzed and it was shown that error is caused more by sensor rotation than by displacements.

\section{FIG. 9 HERE}

If we use the formula (10), external homogeneous fields and first order field gradients are compensated. Fig. 10 shows how effectively is suppressed the lateral current. The meas ured suppression increases fas t with the dis tance: while in the distance of $14 \mathrm{~cm}$ it is 1300 , it is already 93000 in the $40 \mathrm{~cm}$ distance and 4 million in the distance of $1 \mathrm{~m}$. The 
superior current is suppressed ideally as its contribution to $\mathrm{B}_{\mathrm{H}}=\mathrm{B}_{\mathrm{I}}$ and also $\mathrm{B}_{\mathrm{J}}=\mathrm{B}_{\mathrm{K}}$.

\section{FIG. 10 HERE}

\section{CONCLUSION}

By using novel geometry of the fluxgate current transducer we achieve compen sation of external fields and first order field gradients. External superior currents are suppressed completely, while the worst influence have the lateral currents which are suppressed by the factor of 1300 in the $14 \mathrm{~cm}$ distance, which is significanly more that suppression of 66 achieved in the same distance with differential transducer using two fluxgates [2]. The only dis advantage of the proposed solution is that transducer fullscale range was reduced from $1000 \mathrm{~A}$ to $400 \mathrm{~A}$.

\section{ACKNOWLEDGMENT}

This work was supported by the Grant agency of the Czech Republic through the project "New methods for the measurement of electric currents" (GACR 17-19877S). A. Chirtsov was also supported by Texas Instruments.

\section{REFERENCES}

[1] P. Ripka, Electric current sensors: a review, Meas. Science and Technology 21 (2010) Iss. 11, pp.1-23.

[2] P. Ripka; A.Chirtsov: Influence of External Current on Yokeless Electric Current Transducers, IEEE Transactions on Magnetics, 2017, Volume: 53, Issue: 11, paper \# 4003904 , pp. 1-4,

[3] M. F. Snoeij, V. Schaffer, S. Udayashankar, Mikhail V. Ivanov: An Integrated Fluxgate Magnetometer for use in Closed-Loop/OpenLoop Isolated Current Sensing, IEEE J. Solid-state circuits 51 (2016), 1684-1694.

[4] D. Lee, M. Eissa, A. Gabrys et al., "Fabrication and Performance of Integrated Fluxgate for Current Sensing Applications," IEEE Transactions on Magnetics, no. 99, 2017

[5] Pavel Ripka; Vaclav Grim; Vojtech Petrucha: A busbar current sensor with frequency compensation: IEEE Trans. Magn. Vol. 53 (2017), Issue 4, paper \# 4000505

[6] R. Weiss, R. Makuch, A. Itzke, and R. Weigel, "Crosstalk in circular arrays of magnetic sensors for current measurement," IEEE Transactions on Industrial Electronics, vol. 64, no. 6, pp. 4903-4909, 2017.

[7] K.-L. Chen and N. Chen, "A new method for power current measurement using a coreless Hall effect current transformer," IEEE Transactions on Instrumentation and Measurement, vol. 60, no. 1, pp. 158-169, 2011.

[8] M. Blagojevic, U. Jovanovic, I. Jovanovic, D. Mancic, and R. S. Popovic, "Realization and optimization of bus bar current transducers based on Hall effect sensors," Measurement Science and Technology, vol. 27, no. 6, Article ID 065102, 2016.

[9] P. Mlejnek, P. Ripka: Off-center error correction of AMR yokeless current transducer, Journal of Sensors, Volume 2017 (2017), Article ID 6057634

[10] P. Ripka, "4-sensor yokeless electric current transducer," 2017 IEEE International Magnetics Conference (INTERMAG), Dublin, 2017, pp. $1-1$. 


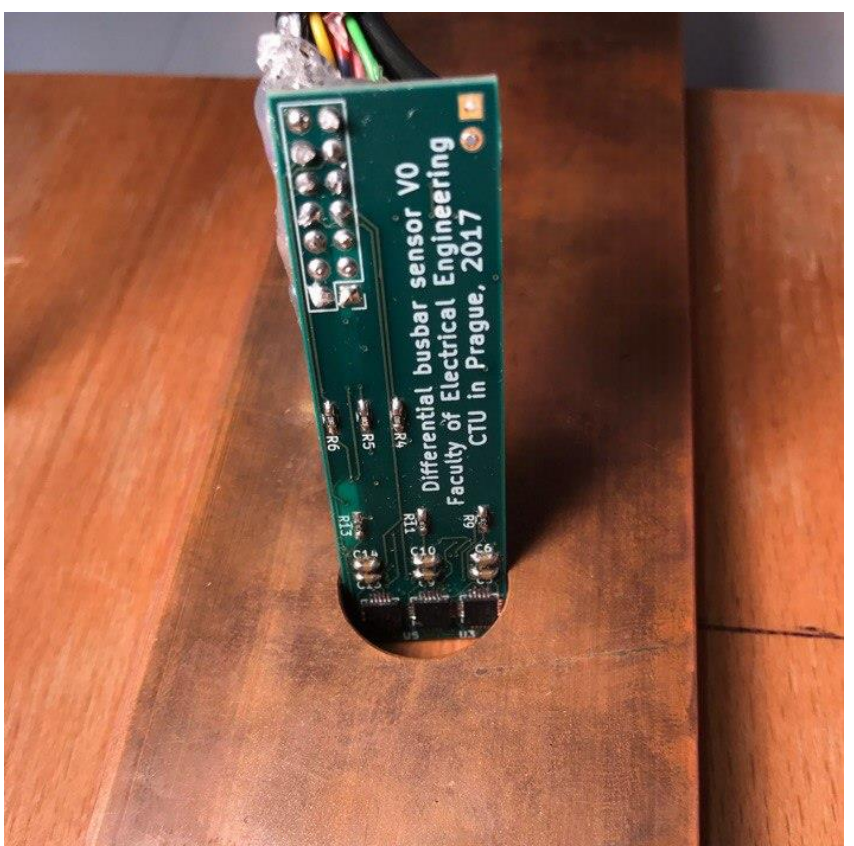

Fig. 1. Current busbar with fluxgate sensor array inserted into the hole

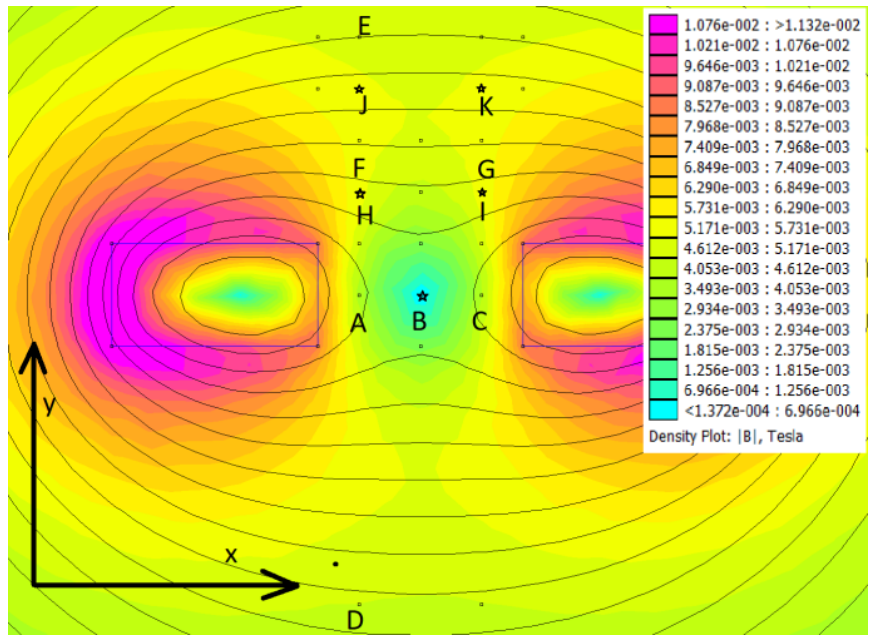

Fig. 2. Field distribution shown on a cross section. The DC current value for this simulation was 1000 A. Final position of the sensors selected for the current transducer is marked by stars

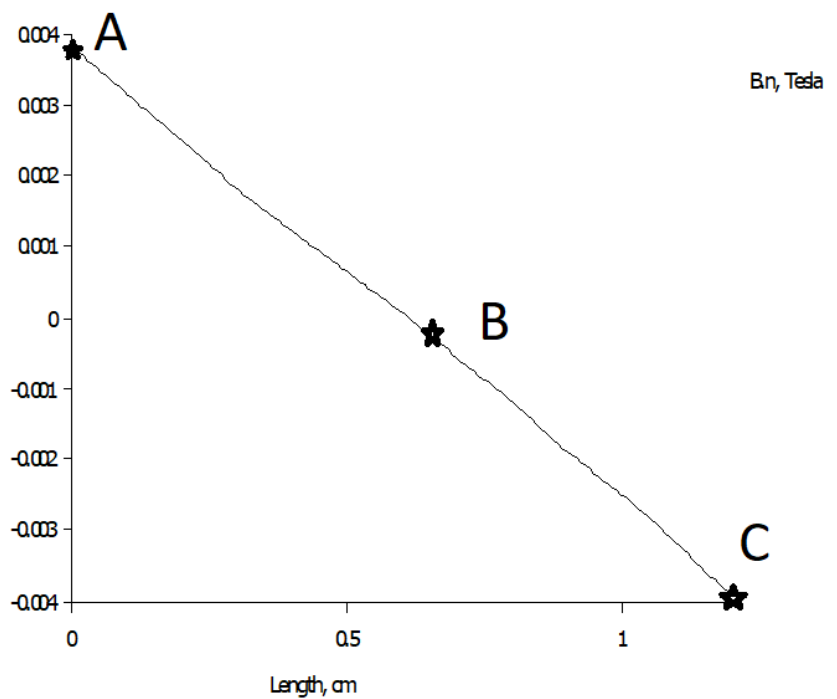

Fig. 3. $\mathrm{B}_{\mathrm{y}}$ field profile from the measured $1000 \mathrm{~A}$ current calculated along the A-C line. Points A, B and C correspond to points in Fig. 2. The stars show position of the sensors according Fig. 2.

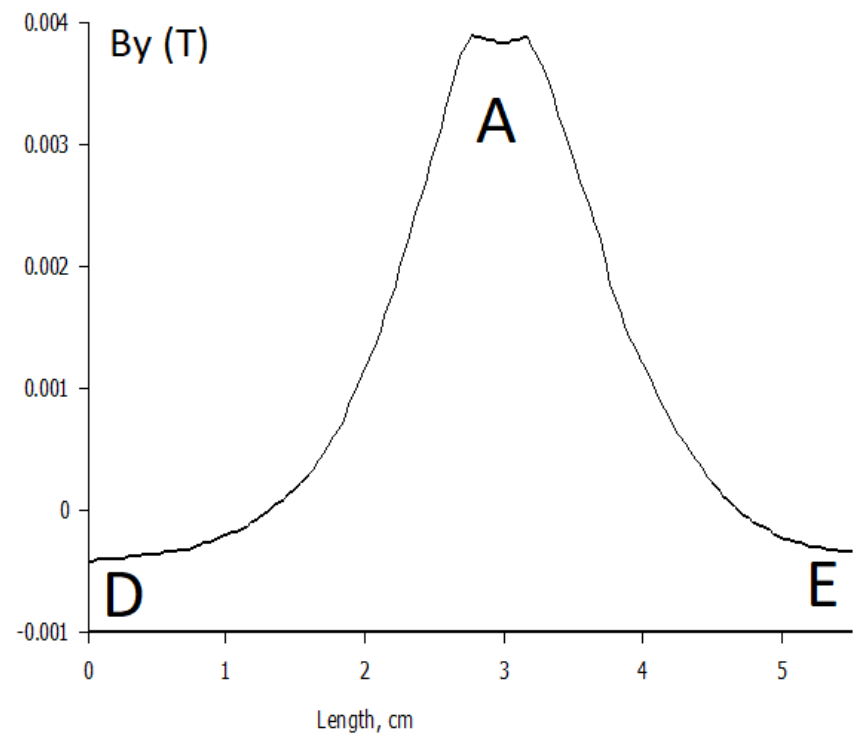

Fig. 4. By field profile calculated across the D- E line 


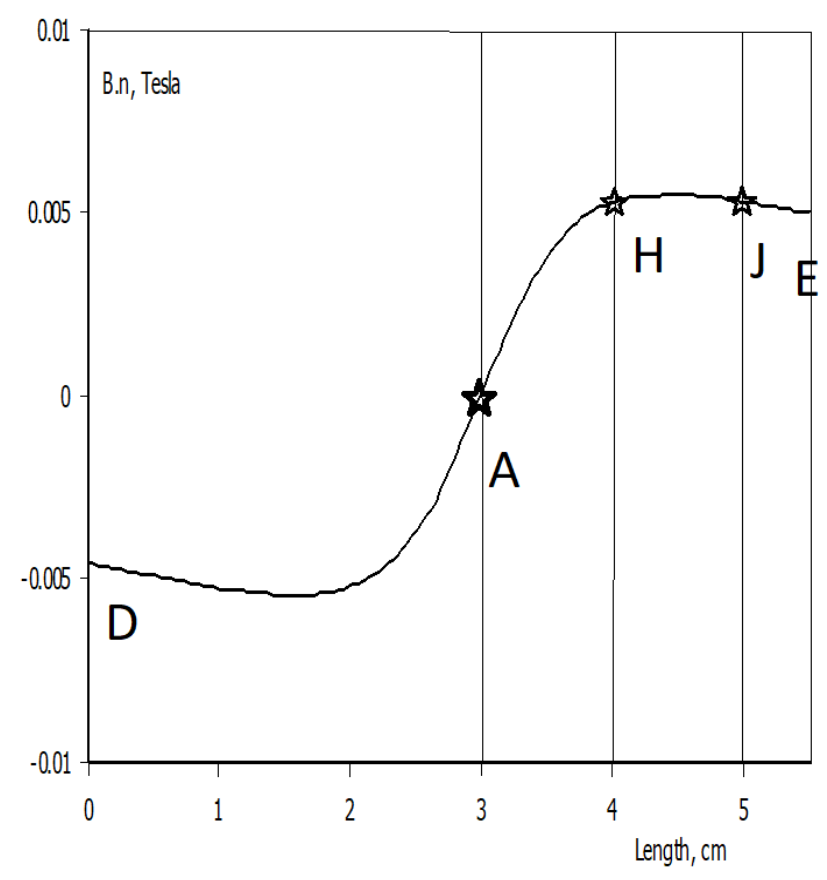

Fig. 5. Bx field calculated along the D-E line. The stars show position of the sensors according to Fig. 2.

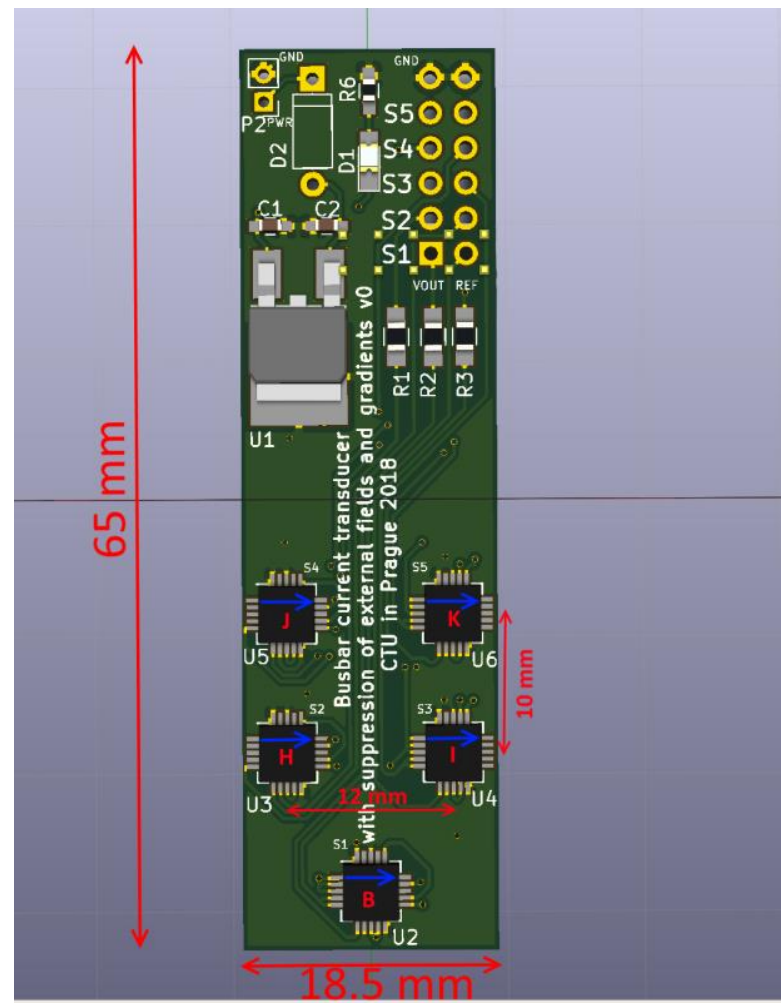

Fig. 7. Photograph of the new transducer in the working position. The Sensor B (at the bottom) is located in the center of the busbar.

Fig. 6: Schematics of our new transducer. Sensors are labeled B,H,I,J and K as shown in Fig. 2 


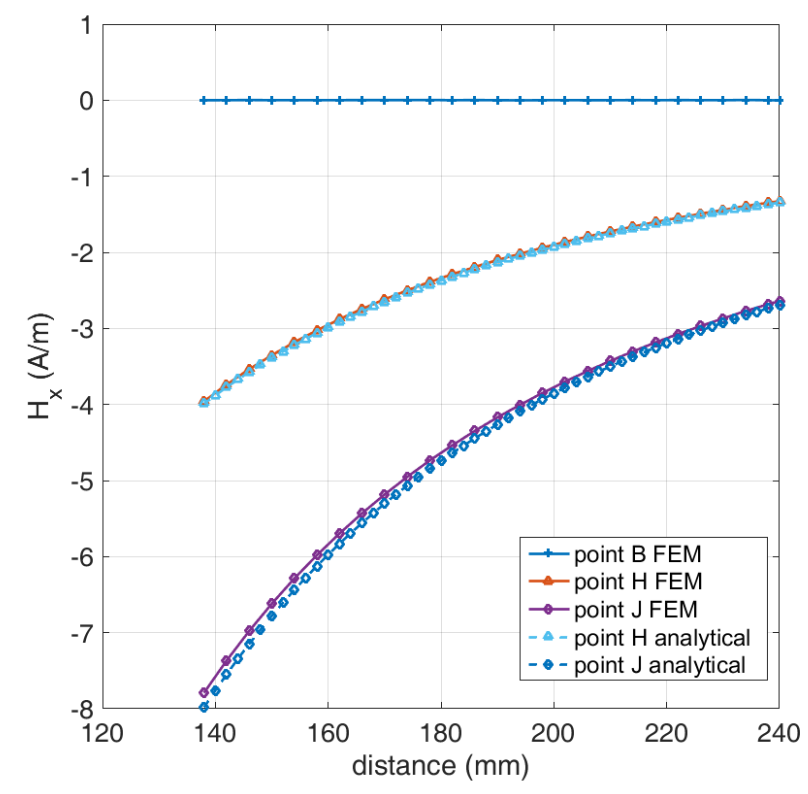

Fig. 8. Response to lateral current - simulation + analytical

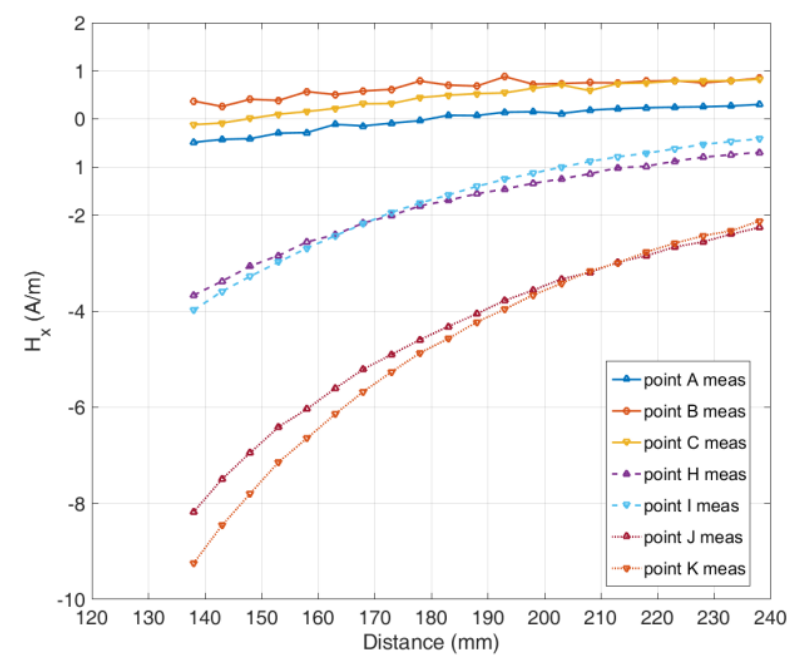

Fig. 9. Response to lateral current - measurement

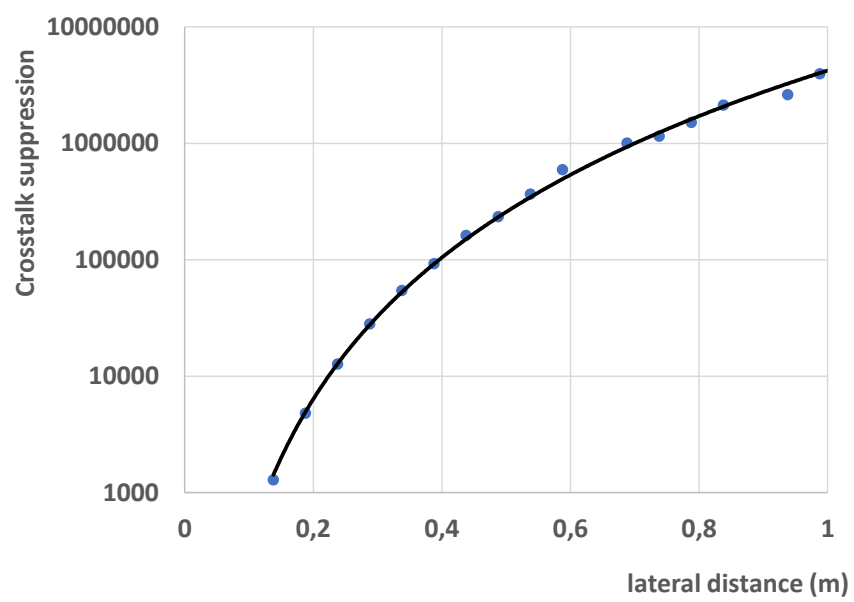

Fig. 10. Crosstalk suppression for lateral external current as a function of its distance - the measured values are shown as datapoints, the line is polynomial trend and serves only as a guide to the eye. 